\title{
Strategies for the implementation of mathematics in Grade R: Teachers' beliefs and practices
}

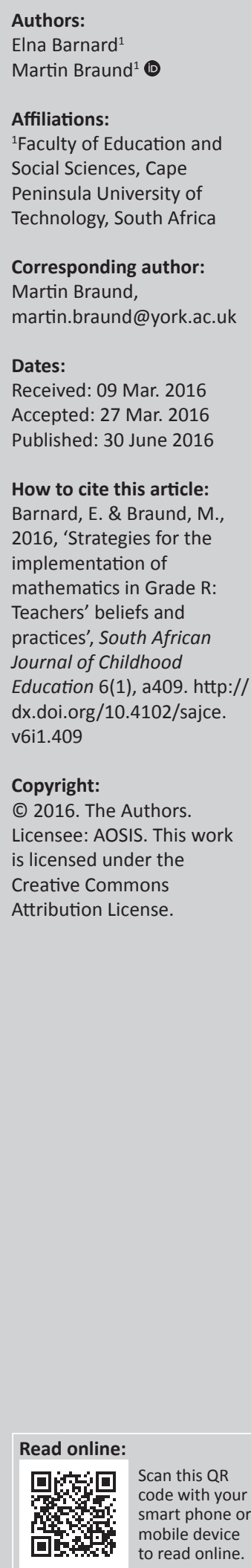

\begin{abstract}
Concerns have been expressed about the quality of teaching and learning in Grade $\mathrm{R}$ (reception) classrooms in South Africa. In mathematics, learning outcomes are said to be particularly limited, especially in poorer provinces of the country (Department of Performance, Monitoring and Evaluation [DPME] 2012). The study reported in this article explored the perceptions and beliefs on teaching mathematics in Grade R, compared with actual classroom practices, of selected teachers in a range of schools and Early Childhood Development Centres in the Eastern Cape. Sixteen teachers took part in focus group meetings, and outcomes were analysed according to Northcutt and McCoy's 'Interactive Qualitative Analysis' method (2004). Themes emerging from analysis were used to construct interview questions and guide observations of Grade R mathematics teaching for nine selected teachers. Findings show that teachers from different contexts have similar perceptions and beliefs about teaching mathematics in grade $\mathrm{R}$ but that often their observed practices do not match how they perceive and value Grade $R$ teaching. In the analysis of lesson videos, we identify a number of 'silent themes' revealing teachers' true actions, enabling us to comment on development and training needed to reach the goals of the intended mathematics curriculum for Grade R.
\end{abstract}

\section{Strategies for the implementation of mathematics in Grade R}

Two recent government-commissioned studies raise concerns regarding the quality of Grade $R$ (Reception) in South Africa. The 'Baseline Study Report' findings on Early Childhood Development $[E C D]$ stressed that 'the quality of learning and teaching in 250 reception year classrooms ... [is] exceptionally low' (Eastern Cape Department of Education [ECDoE] 2008:89, 96). This report further stated that 'the majority of ECD practitioners were teaching as they probably had been taught (teacher-controlled) ... using the traditional teacher-tell methods with passive quiet learners'. An evaluation report by the Presidency of the impact of the Grade R programme (Department of Performance Monitoring and Evaluation [DPME] 2012:4) confirmed that mathematical Grade R learning outcomes are limited, especially in the poorer provinces of South Africa. Based on these concerns, the authors of this article ask why Grade R teaching in South Africa is not making an impact as envisaged, especially regarding mathematics. To explore issues further, we ask what are the experiences of selected teachers of teaching mathematics in Grade R? To answer this question, we look at the role of policy and curriculum for Grade R mathematics and tensions between play and learning mathematics in Grade R. We draw on theoretical perspectives of social constructivism and some of the literature on best practices in learning mathematics in Grade R, and findings of our study with selected teachers in a range of schools and ECD centres in the Eastern Cape Province, to make recommendations that might enhance the impact of teaching mathematics in Grade $R$ classrooms in South Africa.

\section{Policy and curriculum for Grade R mathematics in South Africa}

As background to the study and our research question, one has to look at the history of curriculum development for the early years (mathematics) curriculum since 1997 in South Africa. During 1997, Grade R teachers and practitioners were exposed to several opportunities for in-service training, focussing on the intended outcomes of Grade $\mathrm{R}$ numeracy and mathematics in preparation for the introduction of Curriculum 2005 (C2005), introduced in 1998 as the national curriculum for South Africa (Department of Education [DoE] 1997). However, Curriculum 2005 was revised as early as 2002, when the Revised National Curriculum Statement (RNCS) came to the fore (DoE 2002). The RNCS (DoE 2003) included guidelines for Grade R teachers on how to 
design a numeracy learning programme, work schedules, lesson plans, and teaching and learning materials that stated what learners are expected to attain and accomplish.

In spite of these in-service training initiatives and opportunities, some teachers were still battling to design a Grade R learning programme and felt they needed more hands-on training, not focussed solely on an overview of the latest curriculum developments, but that also included mathematical content, knowledge and skills as well as Grade R mathematical teaching approaches (DoE 2003:14). As a result of this content and skills vacuum, some teachers counteracted their limited methodological knowledge by implementing a formal approach relying on commercially produced resources. Faber and Van Staden (1997) warn against such reliance on commercially bought teaching and learning programmes, as they disempower teachers by focussing on technical pencil and paper requirements instead of what is developmentally appropriate for learners. Additionally, Sawyer (1995) is of the opinion that the frequent use of workbooks can be seen as a cover for teachers to hide gaps in their subject knowledge of mathematics. The practices of Grade $\mathrm{R}$ teachers, who implement a more formal mathematics approach focussing on pencil and paper activities, contrast with recommendations of the interim policy for ECD, which encourages an informal approach that includes hands-on experiences, the use of manipulative materials, questioning, justification of thinking and problemsolving approaches (DoE 1996:5). This policy also recommends that less time should be spent on rote practice and memorisation, the use of worksheets and teaching by telling.

The RNCS was adapted in 2011 when the Curriculum Assessment Policy Standards (CAPS) was phased in (DBE 2011). Once again, Grade $R$ teachers attended training on how to implement the CAPS. Implications of the introduction of the CAPS curriculum for mathematics in grade $R$ are discussed in the following section.

\section{The tension between play and learning mathematics in Grade $\mathbf{R}$}

In spite of informal approaches advocated in curriculum documents, some Grade $\mathrm{R}$ teachers still appear to prefer to let children learn through play freely without setting up, interfering or scaffolding their play activities for learning to take place. For example, according to the 'Baseline Study Report', some learners in ECD sites were 'playing listlessly, without the play environment having been planned and prepared with educational toys and equipment to enhance learning through play' (ECDoE 2008:89). Sheffield and Cruikshank (2000) caution against such laissez faire practice by teachers who allow learners just to play without stimulating and/or enhancing these play activities. Thyer and Maggs (1994) emphasise that children can be happily and busily engaged in play activities, but that these play activities may not lead very far, as far as learning is concerned.
In order to prevent learners just playing without connecting learning, several researchers suggest Grade $R$ teachers plan and set up free play activities whereby young learners are actively exploring, experimenting, discovering, investigating, reasoning and reporting mathematical concepts (Campbell 1997; Kirova \& Bhargava 2002; Sheffield \& Cruikshank 2000):

While children are engaged in an activity, the teacher can observe and then become active in guiding their learning. This interaction will help the children progress from behavioural to representational understanding of mathematical concepts. (Kirova \& Bhargava 2002: unpaginated)

With the introduction of CAPS in 2012, more guidance was provided regarding the integration of mathematical activities in the daily programme as well as determining the time allocated for teacher-directed and learner-focussed mathematical activities. The CAPS Mathematics Grade R policy provided daily mathematical lessons that can be implemented in the Grade $\mathrm{R}$ classroom. In order to supplement the provided mathematical lessons, a Grade R-integrated literacy, numeracy and life skills workbook was introduced in Grade R (DBE 2011). This step was in accordance with the recommendations of the Task Team for the Review of the Implementation of the National Curriculum Statement (DoE 2009:9). However, this initiative is in direct contrast with some of the CAPS principles which advocate, as had preceding curriculum policy documents, that learning in Grade R should take place informally, based on learning through play and integrated activities (DBE 2011:14). Furthermore, the CAPS highlights that teaching practices must make provision for the three stages of learning. Firstly that all learners must experience learning through their five senses, or kinaesthetically, before they move on to a second stage whereby they manipulate various concrete objects. The third stage involves semi-concrete written representations that include drawings and picture cards (DBE 2011:14).

The Evaluation Report stresses that the Grade R classroom and curriculum should not be a 'watered-down' Grade One classroom where learners are expected to start practising formal skills taught in Grade One. 'It requires active, child-centred, participatory methods' (DPME 2012:4).

This rapidly changing policy landscape for the curriculum and its actual impact in the Grade R classroom lead us to consider here, what are the relationships between curriculum policy and observed classroom practices. McKenney, Nieveen and Van den Akker (2006) view curriculum from an inclusive perspective that sees it as a broad definition of a plan for learning used as a starting point, while related views are sought to enhance understanding of the curriculum. Hoadley and Reed, while agreeing that the curriculum can be understood as 'a plan or prescription' (2012:5), go further adding that a planned prescribed curriculum might undergo some changes as it is implemented in the classroom. Hoadley and Reed differentiate between a 'planned (intended) curriculum ... [and a] curriculum-as-practice (enacted curriculum)' (2012:5). McKenney et al., are of the opinion that 
the 'intended curriculum contains both the ideal curriculum (the vision or basic philosophy underlying a curriculum) and the formal/written curriculum (intentions as specified in curriculum documents and/or materials)' (2006:111). Thus, an implemented curriculum contains both the perceived curriculum (interpretations by users, particularly teachers) and the operational curriculum (as enacted in the classroom).

Taking into account the past three curriculum changes in South Africa (C2005, RNCS and CAPS), each can be seen as an intended curriculum whereby Grade $\mathrm{R}$ teachers were expected to implement what was planned. However, it seems that when some Grade R teachers actually implemented the planned and prescribed official curriculum, their practices deviated from its original intentions. Thus, what is being taught and learned in the enacted curriculum in the classroom differs considerably from what was originally envisaged. According to Hoadley and Reed, some of the reasons for different understandings of the curriculum can be found in the teacher, whether it is 'conscious (and sometimes thoughtful) actions by the teacher or as a result of unconscious, thoughtless actions' (2012:38). In South African contexts, other factors such as the availability of resources, large numbers of learners in a classroom and the understanding of the teacher regarding the knowledge, skills and values of how young learners learn, also play significant roles. This article describes and provides an understanding of how Grade $\mathrm{R}$ teachers' experiences, perceptions and beliefs regarding mathematics influence and affect their classroom teaching strategies.

\section{Theoretical perspectives on learning mathematics in Grade $\mathbf{R}$}

A theoretical framework underpinning how young learners develop and learn in mathematics can be found in social cognitive theories. Branscombe et al. are of the opinion that constructivism is 'a theory of knowing that emphasises the role each person plays in constructing his or her knowledge ... this occurs as the individual mentally and often physically acts on the environment' (2002:10). Anghileri (1995) sees young learners perceiving their natural environment through five senses whereby they observe, explore, investigate, experiment, create and do problem-solving. Thus, the young learner will look, hear, touch, smell and taste various objects in their environment. These new experiences are then added or assimilated to their mental constructions regarding their environment. Pritchard (2005:28) adds that new learning occurs when existing mental constructions/schema accommodate or assimilate new schema. However, accommodation takes place when existing mental constructions need to be 'altered in order to cope with the new experience' (Pritchard 2005:24). After accommodation, equilibrium is reached when the new experience of knowledge is no longer strange but becomes part of the existing mental constructions (Pritchard 2005:24).

In order for young learners to construct their own knowledge of their environment, they need other human beings to assist them to come to an understanding of their world. Merely exposing learning to new information is not enough (Schunk 2008:334). Learners need to be actively engaged socially and interact with knowledgeable other significant people. In this interaction, learners will process new information in order for learning to take place. Thus, the theoretical framework of social constructivism is relevant to the mathematical experiences of Grade R teachers in this research study.

\section{The research process}

Taking into account the rapid and major curriculum changes that teachers have had to accommodate since 1998 into cognisance (DoE 2009:24), the following research question is asked: What are the experiences of selected teachers of teaching mathematics in Grade R? In order to contextualise the empirical investigation of teachers' experiences and challenges in teaching mathematics, the following sub-question is also addressed: How do teachers' experiences regarding mathematics influence and affect their teaching strategies in mathematics?

The naturalistic interpretive paradigm, with its emphasis on the understanding and interpretation of Grade R teachers' experiences in implementing mathematics in their classrooms, underpinned this qualitative study with its focus on rich descriptions (Henning, Van Rensburg \& Smit 2004:16). The authors adapted Northcutt and McCoy's (2004) 'Interactive Qualitative Analysis: A Systems Method for Qualitative Research', to investigate how mathematics is perceived and implemented in Grade R.

Sixteen research participants were chosen to participate as a non-probability, convenience, purposeful and criterion case sample. These participants were chosen purposefully as they adhered to the criteria regarding the envisaged provisioning of ECD models, set out by the Education White Paper 5 on Early Childhood Education (DoE 2001) as well as that they would 'provide the best information to address the purposes of the research' (McMillan \& Schumacher 2001:175). By making use of a non-probability case sample, we attempted to obtain rich and in-depth data (Cohen, Manion \& Morrsion 2001:102). The focus of the research study is not meant to be representative of, or generalisable to, the broader ECD community, but merely to have the voices of selected Grade $\mathrm{R}$ teachers heard. These voices were heard when selected Grade $\mathrm{R}$ teachers participated, firstly in unstructured open-ended focus group interviews and secondly in semi-structured individual interviews.

In order to provide opportunities for a wide range of Grade $\mathrm{R}$ teachers to voice their experiences, three open-ended focus group interviews involving a total of 16 teachers were held in three different town and rural settings of the District Office, namely a university town, a coastal town and a farm school setting. During the unstructured and open-ended focus groups, the 16 teachers wrote in silence on small cards what 
their feelings, perspectives and knowledge were regarding their experiences and challenges of teaching mathematics in a Grade R classroom. When teachers were not generating any more cards, they placed completed cards on a wall. The teachers were then invited to move and group their cards as well as their fellow teachers' cards (again in silence) into groups according to the method recommended by Norhcutt and McCoy, 'The participants move, sort, and shift the cards into a cluster group until everyone is satisfied with the categories or groups' (Northcutt \& McCoy 2004:98). Subsequently, the teachers gave a heading or code to the groups or themes they generated and wrote a descriptive paragraph explaining and clarifying each theme. These coded themes were then used to generate an interview framework to direct the individual audio-video taped and the semi-structured interviews with 9 teachers drawn from the original group of 16 .

The nine teachers who participated in the individual audiovideo taped interviews represented teachers teaching at Grade R classes at public township schools, at a private school and Early Childhood Centres. Again, these nine teachers were purposely selected as they not only represented the envisaged provisioning of ECD models in terms of the Education White Paper 5 on Early Childhood Education (DoE 2001) but also because of the fact that they would 'provide the best information to address the purposes of the research' (McMillan \& Schumacher 2001:175).

All the above-mentioned nine participants gave permission for the first author to make audio-video tapes of Grade $\mathrm{R}$ activities in their classrooms. The coded themes, compiled during the focus group interviews, were again used to guide the analysis when audio-video tapes of mathematical activities in the Grade $\mathrm{R}$ daily programme took place. The aim was to record and understand how mathematics is implemented in Grade R classrooms. The activities, progress and outcomes of the lessons were recorded and transcribed as sets of observational narratives.

In analysing transcribed data, John Stuart Mill's Analytic Comparison was used to identify patterns among the coded themes (Neuman 1997:428). Mill's Analytic Comparison comprises two methods, namely the 'Method of Agreement' and the 'Method of Difference' (Neuman 1997:428). The Method of Agreement indicated that there were three categories, consisting of 17 themes, present in all the descriptive narratives from focus groups and interviews. These categories were labelled, 'Barriers', 'Classroom Activities' and 'Teachers' Experiences' (Barnard 2011:21).

By using the Method of Difference to compare the transcripts of the individual interviews with the transcriptions of narratives from lessons audio-videotaped, we found that a new pattern, which we call 'silent themes' came to the fore. We define a silent theme as 'a theme which was not identified during analysis of focus groups or individual interviews, but that became prominent when the observation narratives of the lesson audio-video tapes were analysed' (Barnard 2011:21). The following six 'silent themes' were identified in the nine observation transcripts of the audio-video tapes of classroom activities:

- Silent Theme (a): Educator-centredness;

- Silent Theme (b): A hesitancy by the teacher to do more than what is required by the curriculum policy documents;

- Silent Theme (c): Restricted and narrow questions which do not stimulate learners potential to be creative, to think critically or to reason and attempt to solve problems;

- Silent Theme (d): Non-existence of developmentally appropriate practices;

- Silent Theme (e): Inadequate chances for learning through play;

- Silent Theme (f): An incapacity to arrange and operate the Grade $\mathrm{R}$ class to develop and enrich mathematical abilities of young learners (Barnard 2011:258).

While the above-mentioned themes might be regarded as 'Negative Evidence' (Neuman 1997), we do not view them as discouraging but rather as an opportunity to suggest guidance and support for teachers who need further development in these identified areas. The term 'silent themes' suggests that the participants in the audio-visual recordings were unaware of the impact of their mathematical teaching methodologies in their Grade R classrooms. The teachers' teaching practices in their classrooms are thus inconsistent with what they say and believe about their mathematical knowledge, skills and methodologies. This becomes more apparent in the following section discussing the findings of the study

\section{Discussion of the research findings}

The Method of Agreement (Neuman 1997) indicated that all participants had similar feelings, perspectives and knowledge in terms of the three categories, 'Barriers', 'Classroom Activities' and 'Teachers' Experiences'. Seven of the nine teachers expressed a dire, perceived need for additional training to address barriers experienced in the Grade R classroom. One of the teachers gave a response typical of the perspectives of other participants in the 'barriers' category:

'I don't think it [training] is enough because sometimes you identify a problem but you do not know what to do with the problem. So, if one can go into depth [in training] ... Yes, there is a gap with barriers to learning.'

An appeal was also made for guidance and support regarding the planning and presentation of hands-on mathematical activities. This need for guidance and support was encapsulated aptly by one of the teachers at a public school in a township:

'I need guidance on how to do it [teaching mathematics]. I can try and plan it ... because, there is this planning business. Sometimes you don't know what to do. So sometimes, yes, I need guidance ... because it is a little bit confusing. Sometimes I am not sure whether I do the right thing, or what it is I am doing.' 
In contrast, two teachers who taught at Early Childhood Centres were of the opinion that they were well-trained and knowledgeable regarding classroom activities and how to address barriers to learning. They felt that they do not need further training on how to address barriers to learning or how to plan and implement mathematical activities in the Grade $\mathrm{R}$ classroom. These two teachers attributed their knowledge and skills in this regard to the formal pre-service training they received, as well as the fact that they embarked on personal training. Both these teachers have approximately 38 years' experiences of teaching Grade $\mathrm{R}$ learners:

'You know I think, because of the training I've had and because of the training, I personally am responsible for ... and for the people who have been formally trained, I believe they don't need it. I did the HDE in pre-primary and then after that, which was my fourth year, I continued to do my FDE in pre-primary training at teaching science at the junior primary. I have done the Kindermuzik ... I am a trained facilitator ... a Brain-gym teacher and an Audiblox teacher ... Yes, I have just gone on an integrated learning therapy course [and] I am a daily user ... Uncle Google and I am best buddies.'

One of the principles of the Method of Difference (Neuman 1997) emphasises that the researcher has the obligation to investigate whether there are themes that are not in the data. A recurring phenomenon, not identified by the participants in this study but that came to the fore, was that the participants themselves were ignorant of the fact that their teaching methodologies contribute to challenges learners might experience when mathematics is implemented in their classrooms.

At her interview, a mature teacher from a public school, who previously taught in foundation phase Grades 1 to 3 for more than 20 years but who was now teaching Grade $\mathrm{R}$ for the past 3 years, expressed leanings towards child-centred teaching that seemed to have been an important and valued development in her personal history of practice:

'When I started this Grade R class ... it was teacher-centred. But as years went past, it turned now to be learner-centred. They [the learners] are not restricted in any way. Sometimes they choose what to do ... not always. No, their [spatial and numeracy] concepts are just okay, because [these] concepts are always in their daily life. Like ... position and space, front, back, side, under, on top of, positions ...'

However, when this same teacher presented an outside movement activity, whereby these mathematical concepts can be integrated, video-recording of her lesson depicted her actions to be in direct contrast to what she espoused as good mathematics teaching for Grade R, as can be seen in this excerpt from the lesson observation narrative:

The teacher put out 4 hoops and 2 rings. The teacher showed the learners how to twist with the hoops. The teacher then initiated a racing game - she explained how the game was to be played and facilitated the playing of it whereby the learners had to run 5 metres, crawl through a hoop, run around a child and run back to the group for the next child to start. The teacher initiated a game with ropes whereby some learners were handling the ropes and others had to jump. The teacher assisted in organising the children to jump and twisted one end of the rope. The teacher initiated a ball game whereby she threw the ball to learners they caught it and threw it back to her. The teacher initiated and facilitated the 'cat and mouse' game.

In this lesson, and counter to this teacher's expressed beliefs about learning, there were very few chances for learners to initiate their own movement and play activities or to interact and respond to teacher questions. There was no discussion that linked movements to mathematical concepts, for example, of length and time, or that might have allowed problem-solving or critical thinking about the manipulation of hoops or how these behaved (spinning, rolling, oscillating and so on). The main discrepant 'silent themes' in this area were seen to be educator-centeredness, a hesitancy by the teacher to do more than what is required by the curriculum policy documents as well as restricted and narrow questions that do not stimulate learners' potential to be creative, think critically or reason and attempt to solve problems.

A teacher, with 5 years teaching experience and who teaches in a private school in the town, seems to base her teaching methodology on learning through play. At her interview she said:

'... the learners learn a lot because they learn to play. They don't know that they are learning, but they are learning. They like to be involved in all activities. There are hyperactive learners that always need your attention and supervision. What I do then is making sure that I'm keeping them busy. That is the only way to control them. If he is finished doing this, you should give him another thing to do. The only thing you (do to) make them to learn is to keep them busy all the time.'

By making use of a computer in her class, this teacher exposed learners to mathematical concepts as this excerpt from the lesson observation narrative shows:

The teacher and one learner faced a computer while the rest of the learners sat on the carpet watching what was happening on the small computer screen. Two games were played; one where the leaner had to match the size of people's feet, while the other game involved counting cookies out for a horse. All the 25 learners were very excited to use the computer and to play a game on it, but only a few (6) had the opportunity to do this, while the rest of the group watched. The teacher assisted the learner in front of the computer in handling the computer mouse but did not engage in any discussion regarding why a certain computer action was being used, nor did she ask any guiding questions.

As illustrated in this excerpt, learning through play only took place for six learners while others were passive, watching what was going on in front of them. Thus, although the teacher says she believes in learning through play and intends to involve learners actively, her teaching actions revealed 'silent themes' showing inadequate chances for learning through play and non-existence of developmentally appropriate practices. In the latter case, we take the view that it is not developmentally appropriate for learners to sit passively watching a few friends executing a computer 
programme in a haphazard way unsupported by teacher questioning or intervention.

The sixth of our 'silent themes', namely an incapacity to arrange and operate the Grade $\mathrm{R}$ class to develop and enrich mathematical abilities of young learners, came to the fore when a novice Grade $\mathrm{R}$ teacher, who used to work in a bank but is now doing part-time studies to obtain a BEd Foundation Phase degree, engaged with her learners during the mathematical focus time. At her interview, this teacher said:

'I work with the learner that wants to participate. I am not forcing a child when he does not want to participate. I give them worksheets ... they are past the time for playing ... I begin to work more formally. Yes, they must count every day in order for them to be aware of numbers. I ask the Grade One teachers, 'with what they are experiencing difficulty with" and they said, "it was the numbers 1 to $10^{\prime \prime}$. Therefore, I focus on numbers 1 to 10 in order for them to grasp it. I concentrate on counting activities in mathematics.'

Although this teacher is working more formally with the learners, her classroom organisation and management seemed to be a stumbling block in ensuring productive mathematical learning activities, as this excerpt from the lesson observation narrative shows:

\begin{abstract}
... this teacher's classroom was untidy and disorganised, with limited space on the carpet for 46 learners to participate in whole group discussions, focussing on counting and sorting of shapes. The teacher had no control in her classroom. While she was conducting the group discussion, some learners were eating, walking around, fiddling and even stumbling and falling. There was more than one discussion going on at the same time, even while the teacher was giving instructions or trying to explain to the learners what must be done. Many of the 46 learners were not concentrating - although the learners were instructed to complete the worksheet, some preferred to play and took the bear from the cupboard. One girl was sweeping the floor in order not to participate in the activities. The worksheet (A4) was too small for 46 learners to see how many shapes and animals there were on it. No individual attention was given to learners as questions were asked to no one specifically and some learners shouted out the answers. The shapes (square, circle and triangle) were too small and made out of flimsy paper for all the learners to feel it in their group. Again, not all learners participated in the shapes and counting activities as some of them were wrestling on the carpet or played with a ball in the class. The teacher took a laissez-faire approach and had little or no control over the class.
\end{abstract}

Although this teacher acknowledged that she experiences challenges in her classroom, she does not seem to realise that the absence of a well-planned and organised classroom, especially relating to available resources, has a negative impact on the learning activities. She is of the opinion that the discipline problems she experiences are a result of overcrowding and the disruptive behaviour of learners. She said:

'Yes, resources are a problem. When I receive new resources, I am afraid to put them out as they will be broken. They cannot play correctly with the toys, they storm at it and then it breaks. Yes, yes, I cannot turn my back ... but when they are so many, I cannot identify who is making the noise. ... it is a big frustration. Therefore I played two days sick and stayed at home.'

\section{Conclusion and recommendations}

The aim of this research was to provide an understanding of what the experiences of selected teachers are when they teach mathematics in their classrooms as well as how these experiences affect their teaching strategies. The findings of the research reveal that teachers' beliefs, perceptions and teaching actions do affect their teaching. But more importantly, the examples from 'silent themes', shows that their actions (irrespective of whether intentional), as an enacted curriculum, vary greatly from the intended one.

In answering our research question, 'What are the experiences of selected teachers of teaching mathematics in Grade R?', we draw on our research findings and relevant literature to guide discussion and recommendations regarding Grade $\mathrm{R}$ mathematics. Focussing on data analysis from the focus group and semi-structured individual interviews, it seems as if some Grade $\mathrm{R}$ teachers do have some (rather limited) general knowledge regarding teaching mathematics in Grade R. The Baseline Study Report supports this finding 'practitioners know what their roles and responsibilities are' (ECDoE 2008:90). However, comparing the beliefs, attitudes, perspectives and knowledge of teachers in our study with their classroom practices revealed that some of these teachers' experiences of mathematics teaching influence and affect their teaching strategies somewhat negatively. Our observations that for some of these teachers mathematics may not be being implemented throughout the day programme in the Grade R classroom in a developmentally appropriate way cannot be attributed solely to teachers' lack of sound Grade R methodology. The backgrounds, training and teaching experiences of Grade R teachers could positively affect their day-to-day implementation of mathematics, as illustrated by the two teachers who received formal preservice training, specialising in ECD. The other seven teachers interviewed and observed were either formally trained as Junior Primary Teachers or were in the process of receiving in-service training. However, The Baseline Study Report (ECDoE 2008:89) found that many of the Grade R teachers in the Eastern Cape, in spite of their training, still taught in a teacher-centred way while their learners were not participating in activities:

The majority of ECD practitioners were teaching as they probably had been taught (teacher-controlled) ... using the traditional teacher-tell methods with passive quiet learners. (ECDoE 2008:89)

Although the National Curriculum Statement (2011) prescribes mathematical content for Grade R, it is our contention that the enacted curriculum will only reflect the principles of the intended curriculum if Grade $\mathrm{R}$ subject advisors and mathematics curriculum specialists from the provincial and district education offices support and guide 
Grade $\mathrm{R}$ teachers in how to implement mathematics. This requires promoting and presenting Grade $\mathrm{R}$ mathematics in a hands-on, developmentally appropriate manner, using activities that involve and engage learners and that open spaces for learner creativity and critical thinking. Teachers' understanding of the intended curriculum has been clouded by the three rapidly introduced curricula, C2005, RNCS, CAPS and their guiding principles, implemented since 1997. Therefore, appeal for support visits, as expressed by one of the teachers in this study should not be ignored:

'Yes, I wish someday ... just one day ... to get someone to come and tell me maybe this activity is for this one (this learning objective) ... this is the activity ... Yes.'

Education departments as well as other training organisations such as universities, FET colleges, resource and training organisations all need to play a part in ensuring that Grade $R$ teachers and their school management teams understand what is meant by productive learning through play, in order to ensure that it takes a high priority in the Grade $\mathrm{R}$ day programme (DBE 2011:14). Because of the fact that some teachers in our study did not fully understand the importance of learning through play, they seemed not to be able to provide mathematical activities whereby learners experienced concepts through exploration, experimentation and problemsolving activities. In contrast, some Grade $\mathrm{R}$ teachers rather gave their learners worksheets to complete as in Grade 1.

Overreliance on formally constructed activities with outcomes that require a written record suggest that teachers prefer formal writing to play activities, because 'the formal approach has measureable results, whilst the results of free play cannot easily and directly be determined' (Jones 2005:202). Faber and Van Staden (1997) point out that learners engaged in problem-solving activities in worksheets need only to choose a calculation procedure. In contrast, Grouws and Good (1989) stress the importance of discussing and explaining how a mathematical problem is solved.

One of the teachers in our study did provide movement and play activities, but joined in the activities with the learners. It is possible that this teacher sees a reason, as Jones suggests (Jones 2005:201), for teacher domination of play activities to limit discipline problems. However, we believe that subject advisors could be used to guide teachers not to dominate play activities, perhaps showing examples of good practice where this can be done.

In conclusion, the experiences of selected teachers of teaching mathematics in Grade R in our study varied. Some teachers felt confident when they planned and guided learners to discover mathematical concepts, while others experienced frustration and a need for further training, especially in how to enact the intended curriculum. This frustration and uncertainty had a negative impact in some classrooms, especially when mathematical activities are presented. However, circumstances such as the background and training experiences of teachers contribute to this feeling of either being confident or frustrated. Despair and frustration can also be attributed to the fact that some Grade $\mathrm{R}$ teachers are teaching in 'silos' with limited support from district officials and/or school management teams, especially when the emphasis of teaching mathematics should be on experimenting, exploring, discovering and discussing how the problem was solved, thus learning through play in action. The understanding and deployment of developmentally appropriate mathematics in Grade $\mathrm{R}$ forms the bedrock for further mathematics learning. For meaningful practice to develop in South African schools, requires stakeholders in schools, FE, HE and at government, departmental and provincial levels, to make a coordinated and system-wide effort.

\section{Acknowledgements Competing interests}

The authors declare that they have no financial or personal relationships which may have inappropriately influenced them in writing this article.

\section{Authors' contributions}

E.B. carried out the research and was responsible for design of the research instruments and collection and analysis of all the data. M.B. was Adjunct Professor for Research Capacity Development at CPUT at the time of writing and made suggestions on conceptual progression and argument structure within the article and assisted with editing and production of the final manuscript.

\section{References}

Anghileri, J., 1995, Children's mathematical thinking in the primary years: Perspectives on children's learning, Cassell, London.

Barnard, E., 2011, 'An investigation into Grade R teachers' experiences of implementing numeracy in Grade R', Unpublished PhD thesis, Rhodes University, Grahamstown,

Branscombe, N., Castle, K, Surbeck, E. \& Taylor, J.B., 2002, Early childhood curriculum: A constructivist perspective, Houghton Mifflin Company, Boston, MA.

Campbell, P.F., 1997, 'Connecting instructional practice to student thinking', In D.L. Chambers (ed.), Putting research into practice in the elementary grades. Readings from Journals of the National Council of Teachers of Mathematics, NCTM, Reston, VA.

Cohen, L., Manion, L. \& Morrison, K., 2001, Research methods in education, 5th ed., Routledge Falmer, London.

Department of Basic Education (DBE), 2011, Curriculum and assessment policy statement Grade R. Mathematics, Department of Basic Education (DBE), Pretoria.

Department of Education (DOE), 1996, Interim policy for early childhood development, Department of Education (DOE), Pretoria.

Department of Education (DOE), 1997, Foundation phase (grades $R$ to 3) policy document, Government Printer, Pretoria.

Department of Education (DOE), 2001, Education white paper 5 on early childhood education: Meeting the challenge of early childhood development in South Africa, DOE, Pretoria.

Department of Education (DOE), 2002, Revised national curriculum statement grades $R-9, \mathrm{DOE}$, Pretoria.

Department of Education (DOE), 2003, Revised national curriculum statement grades $R-9$ (Schools). Teacher's guide for the development of learning programmes: Foundation phase, DOE, Pretoria.

Department of Education (DOE), 2009, 'Report of the task team for the review of the implementation of the national curriculum statement', viewed 9 October 2010 from http://docs.google.com/viewer?a=v\&q=cache:_9T6Drnfco8J:www.info.gov. za/view/DownloadFileAction\%3Fid\%3D123634

Department of Performance Monitoring and Evaluation in the Presidency (DPME), 2012, The impact of the introduction of Grade $R$ on learning outcomes, DPME, Pretoria.

Eastern Cape Department of Education (ECDoE), 2008, The evaluation of the accredited training of early childhood development practitioners. Baseline study: Quality of teaching and learning in Grade R, Quality Promotion and Standards Directorate, East London. 
Faber, R. \& Van Staden, C., 1997, The year before school: A year of learning, Heinemann, Sandton.

Grouws, D.A. \& Good, T.L., 1989, 'Issues in problem-solving instruction', In D.L. Chambers (ed.), Putting research into practice in the elementary grades. Readings from Journals of the National Council of Teachers of Mathematics (NCTM), NCTM, Reston, VA.

Henning, E., Van Rensburg, W. \& Smit, B., 2004, Finding your way in qualitative research, Van Schaik, Pretoria.

Hoadley, U. \& Reed, Y., (eds.), 2012, Curriculum: Organising knowledge for the classroom, 3rd ed., Oxford University Press, Cape Town.

Jones, B.J., 2005, 'Play in early childhood', In T. Maynard \& N. Thomas (eds.), An introduction to early childhood studies, Sage Publications, London.

Kirova, A. \& Bhargava, A., 2002, 'Learning to guide preschool children's mathematical understanding: A teacher's professional growth', Early Childhood Research \& Practice 4(1). viewed 18 October 2010, from http://ecrp.uiuc.edu/v4n1/kirova.htm

McKenney, S., Nieveen, N. \& Van den Akker, J., 2006, Education design research, Routledge, New York.
McMillan, J.H. \& Schumacher, S., 2001, Research in education: A conceptual introduction, 5th edn., Addison Wesley Longman, New York.

Neuman, W.L., 1997, Social research methods qualitative and quantitative approaches, 3rd ed., Allyn and Bacon, Boston, MA.

Northcutt, N. \& McCoy, D., 2004, Interactive qualitative analysis: A systems method for qualitative research, Sage, London.

Pritchard, A., 2005, Ways of learning: Learning theories and learning styles in the classroom, David Fulton Publishers, New York.

Sawyer, A.E., 1995, Developments in elementary mathematics teaching, Heinemann, Portsmouth, $\mathrm{NH}$.

Sheffield, L.J. \& Cruikshank, D.E., 2000, Teaching and learning elementary and middle school mathematics, 4th ed., John Wiley, New York.

Schunk, D.H., 2008, Learning theories: An education perspective, 5th edn., Pearson Merrill Prentice Hall, NJ.

Thyer, D. \& Maggs, J., 1994, Teaching mathematics to young children, 3rd edn., Cassell Education Limited, London. 